\title{
EFFICACY OF ALBENDAZOLE, ALBENDAZOLE-LEVAMISOLE AND MEBENDAZOLE-LEVAMISOLE AGAINTS SOIL-TRANSMITTED HELMINTH INFECTION IN SCHOOL CHILDREN, DELI SERDANG, NORTH SUMATERA
}

\author{
Endy Julianto1), AA Depari²), Endang Haryanti Gani1 ${ }^{1)}$ \\ 1) Department of Parasitology, Faculty of Medicine, \\ Methodist University, Medan \\ 2) Department of Parasitology, Faculty of Medicine, \\ North Sumatera University, Medan
}

\begin{abstract}
BACKGROUND: Intestinal worm infection in particular of Soil Transmitted Helminth (STH) remained an important global public health problem, with high prevalence existed in the tropic and sub-tropic regions, including Indonesia. The prevalence was higher in rural than urban community. Helminthiasis (worm infection) is a chronic infection of nematode worm, which comprised $A$. Lumbricoides, T. trichiura, $N$. Americanus, and A. duodenale. This infection can cause physical and intellectual retardation in children. This study aimed to examine the efficacy of Albendazole, Albendazole-Levamisol, and MebendazoleLevamisol in intestinal worm eradication.

SUBJECT AND METHODS: This was a double-blind randomized controlled trial, conducted in Deli Serdang, North Sumatera, from April to June 2015. A sample of 180 primary school children was allocated in 3 groups: (1) Albendazole $400 \mathrm{mg}$; (2) Albendazole $400 \mathrm{mg}$-Levamisol 50 $\mathrm{mg} / 100 \mathrm{mg}$; and (3) Mebendazole $500 \mathrm{mg}$-Levamisol $50 \mathrm{mg} / 100 \mathrm{mg}$. The independent variable was anti-helminthiasis consisting of Albendazole $400 \mathrm{mg}$, Albendazole $400 \mathrm{mg}$-Levamisol $50 \mathrm{mg} / 100 \mathrm{mg}$, and Mebendazole $500 \mathrm{mg}$-Levamisol $50 \mathrm{mg} / 100 \mathrm{mg}$. The dependent variable was STH infection, which was examined from the stool using Kato-Katz method. The stool was collected and examined on day-7, day-14, and day21 after treatment. The other dependent variable was side effect of the treatment.

RESULTS: The types of STH infection were as follows: 92 (51.11\%) Ascariasis, 37 (20.55\%) Trichuriasis, and 51 (28.33\%) mixed infection. The cure rate for A. lumbricoides infection was $100 \%$ in all groups. The cure rate of $T$. trichiura infection was $66.7 \%$ for Albendazole, $94.7 \%$ for Albendazole-Levamisol, and $92.3 \%$ for Mebendazole-Levamisol, and this difference was statistically significant $(\mathrm{p}<0.001)$. The cure rate for mixed infection was 28.6\% for Albendazole, 85.7\% for Albendazole-Levamisol, and $66.7 \%$ for Mebendazole-Levamisol and this difference was statistically significant $(\mathrm{p}<0.001)$. The cure rate of mild T.trichiura infection by singledose Albendazole-Levamisol was better than either Albendazole or Mebendazole-Levamisole $(\mathrm{p}=0.010)$. Nausea and diarrhea were present in all treatment groups, but the difference was not statistically significant.
\end{abstract}


CONCLUSION: Albendazole was more efficacious than either Abendazole-Levamisol or Mebendazole-Levamisole to T. trichiura and mixed infection. All anti-helminthic cure $100 \%$ of $A$. lumricoides. The best treatment for mild $T$. trichiura infection is single dose AlbendazoleLevamisol.

Keywords: Soil Transmitted Helminth, Albendazole, AlbendazoleLevamisol, Mebendazole-Levamisol 